\title{
Regeneration of Neural Networks in Immature Teeth with Non-Vital Pulp Following a Novel Regenerative Procedure
}

\author{
Maha M. F. Mounir ${ }^{1,2}$, Fatma M. Rashed ${ }^{3}$, Sahar M. Bukhary ${ }^{4}$ \\ ${ }^{1}$ Department of Oral Diagnostic Sciences, Faculty of Dentistry, King Abdulaziz University, Feddah, Saudi Arabia \\ ${ }^{2}$ Faculty of Dentistry, Alexandria University, Alexadria, Egypt \\ ${ }^{3}$ Department of Oral Biology, Faculty of Dentistry, Damanhour University, Damanhour, Egypt \\ ${ }^{4}$ Department of Oral Biology, King Abdulaziz University, Faculty of Dentistry, Feddah, Saudi Arabia
}

\begin{abstract}
Background and Objectives: Recombinant amelogenin protein (RAP) was reported to induce soft-tissue regeneration in canine infected endodontically treated permanent teeth with open apices. To characterize identities of the cells found in the RAP regenerated tissues compared to authentic pulp by identifying: 1) stem cells by their expression of Sox2; 2) nerve fibers by distribution of the axonal marker peripherin; 3) axons by their expression of calcitonin gene-related peptide (CGRP); 4) the presence of astrocytes expressing glial fibrillary acidic proteins (GFAP).

Methods: A total of 240 open-apex root canals in dogs were used. After establishment of oral contamination to the pulp, the canals were cleaned, irrigated, and 120 canals filled with RAP, and the other 120 with calcium hydroxide. Results: After 1, 3, and 6 months, teeth were recovered for immune-detection of protein markers associated with native pulp tissues. Regenerated pulp and apical papilla of RAP group revealed an abundance of stem cells showing intense immunoreactivity to Sox2 antibody, immunoreactivity of peripherin mainly in the A-fibers of the odontoblast layer and immunoreactivity to CGRP fibers in the central pulp region indicative of C-fibres. GFAP immunoreactivity was observed near the odontoblastic, cell-rich regions and throughout the regenerated pulp.

Conclusions: RAP induces pulp regeneration following regenerative endodontic procedures with cells identity by gene expression demonstrating a distribution pattern similar to the authentic pulp innervation. A- and C-fibers, as well as GFAP specific to astrocytic differentiation, are recognized. The origin of the regenerated neural networks may be derived from the Sox2 identified stem cells within the apical papilla.
\end{abstract}

Keywords: Amelogenin, Dental pulp necrosis, Apical periodontitis, Calcitonin gene-related peptide, Glial fibrillary acidic protein, Peripherin, Sox2, Stem cell homing, Regenerative endodontics

Received: February 17, 2019, Revised: July 17, 2019,

Accepted: August 22, 2019, Published online: October 31, 2019

Correspondence to Maha M. F. Mounir

Department of Oral Diagnostic Sciences, Faculty of Dentistry,

King Abdulaziz University, Jamaa District, King Abdulaziz

University, P.O. Box 80209, Jeddah 21589, Saudi Arabia

Tel: +966-2-640-3443 ext: 22024, Fax: +966-2-640-3316

E-mail: maha.f.mounir@gmail.com

(c) This is an open-access article distributed under the terms of the Creative Commons Attribution Non-Commercial License (http://creativecommons.org/ licenses/by-nc/4.0/), which permits unrestricted non-commercial use, distribution, and reproduction in any medium, provided the original work is properly cited.

Copyright (C) 2019 by the Korean Society for Stem Cell Research

\section{Introduction}

The dental pulp is a highly specialized mesenchymal tissue characterized by the presence of odontoblasts and surrounded by a rigid, mineralized dentinal matrix. Dentin is synthesized by odontoblasts, which are derived from cranial neural crest (1). Human dental pulp is infiltrated by a network of blood vessels and is highly innervated by nerve bundles emerging from the apical region. It has a sophisticated sensory function (2).

The management of an incompletely developed tooth with necrotic pulp has always been a challenge within the 
field of endodontics. In such cases, root formation has not completed and the apex remains open until approximately 3 years after eruption of the tooth (3). Filling the root canal is difficult because the open apex does not provide a barrier to stop the root filling material before it reaches the periodontal tissues. Cleaning and shaping these canals leaves the already thin dentin walls further susceptible to fracture. Apexification is a method to induce a calcified barrier in a root with an open apex in a tooth with necrotic pulp (4). Regenerative endodontic therapy provides an alternative approach for successfully treating these challenging cases by regenerating functional pulp tissue.

Angiogenesis, vasculogenesis and neurogenesis are essential for pulp regeneration. Pulp vitality is extremely important for tooth viability, since the pulp provides nutrition and acts as a biosensor to detect pathogenic stimuli $(5,6)$.

Sensory innervation of the dental pulp is mediated by axons originating from the trigeminal ganglia (TRG). There are many $\mathrm{A} \delta$ - and C-fibers in the tooth-pulp, with the $\mathrm{A} \delta$-axons ending mostly in the inner third of the dentinal tubules and the C-fibers ending mostly in the pulp tissue proper, either as free nerve endings or as branches around blood vessels. A $\delta$ - and C-nociceptors dominate intrinsic tooth innervation. Calcitonin gene-related peptide (CGRP) is a 37-amino acid peptide, primarily localized to $\mathrm{C}$ and $\mathrm{A} \delta$ sensory fibers; it is produced in both peripheral and central neurons. These fibers display a wide innervation throughout the body especially in the dental pulp; CGRP is primarily released from sensory nerves and thus is implicated in pain pathways. CGRP is normally associated with synaptic transmission by C-fiber nociceptors. These fibres have a dual role in sensory (nociceptive) and efferent (effector) function. In the trigeminal vascular system, the cell bodies on the trigeminal ganglion are the main source of CGRP; it also contributes to the regeneration of nervous tissue after injury (7-10), while A-fibers could mainly be detected using antibodies to peripherin (11).

Cell populations already present in a patient's body, including stem/progenitor cells that can be actively attracted to sites of injury for in situ tissue regeneration is defined as endogenous cell homing. Cell homing has the potential to provide new therapeutic options, an alternative to adoptively transferred stem cells. It offers new insights into in vivo tissue engineering (12). Stem cells are crucial to pulp regeneration and maintaining its vitality. Cell fate determination of a pluripotent stem cell is controlled by both extrinsic and intrinsic factors. The intrinsic factors include transcription factors that play an essential role in direct control of gene expression in the cells. Among these intrinsic factors, the most important for regulating pluripotency are Octamer-binding transcription factor 4 (Oct4), Sox2 and Nanog (13). Sox2 plays important roles in regulating and maintaining the pluripotency of stem cells, and also in directing their neural differentiation. Sox 2 has also been proposed to regulate mesoderm and ectoderm differentiation. In addition, Sox 2 functions to maintain the self-renewal of neural progenitor stem cells in vitro as well as in vivo $(14,15)$.

An important theme currently under investigation is the neurological basis of the sensory functionality of dental pulp. Magloire et al. (8) investigated the sensory role of odontoblasts and the interaction of these cells with neural elements. Farahani et al. (16) demonstrated the presence of a sophisticated neural structure in the human dental pulp that is analogous to other central sensory organs, and concluded on this basis that the dental pulp is a vestigial sensory organ co-opted to synthesize mineralized matrix. Structural analysis by confocal laser scanning microscopy showed three distinct cell populations adjacent to odontoblasts, namely GFAP + (glial fibrillary acidic protein) seracytes, S100 + telacytes and HLA-II + alacytes. These cell populations were identified in peripheral human dental pulp, and are the essential elements of neuro-sensory organs. Subsequent molecular fingerprinting by quantitative RT-PCR established these cells as analogous to radial glia (GFAP + cells), astrocytes (S100+ cells), and microglia (HLA-II + cells) of central nervous system organs. In the cell-rich zone of the pulp, S100+ cells formed a network, ensheathed unmyelinated axons and extended end-feet around the capillaries. Glial cells have multiple functions during the development of the peripheral nervous system (PNS) and in repair process. During early PNS development, axonal signals are critical for Schwann cell migration, survival and proliferation (11).

Here, we investigate the stem cells that show immunoreactivity to Sox 2 antibody and their relationship to the regeneration of the neural networks present in regenerated dental pulp following regenerative endodontics with amelogenin protein, specifically with regard to the presence and distribution of the two populations of dental nerve fibers, the CGRP-reactive type and the Peripherin-reactive type.

\section{Materials and Methods}

\section{Animal preparation}

Details of all procedures were previously described by Mounir et al. (17). A total of 24 mongrel dogs of 6 months 
of age were included in this study. Animals were maintained and observed for health assessment before any endodontic procedures were performed. Approval for the procedures was obtained from the Institutional Review Board for the safety and protection of vertebrate animals, Pharos University, Alexandria, Egypt. All procedures were carried out under aseptic conditions and general anesthesia.

After each surgery, the animals received Voltaren (Novartis Pharma Egypt, under license from Novartis Pharma, Switzerland), an intravenously delivered painkiller, at $25 \mathrm{mg} / \mathrm{kg}$. Tetracycline (Tetracid; Cid Co, Egypt) was administered intramuscularly the first day and thereafter mixed with food for 7 additional days at a dose of $15 \mathrm{mg} / \mathrm{kg}$. The dogs were placed on a soft diet during the postoperative period to reduce the possibility of local trauma to the surgical site.

After 1, 3 or 6 months postoperatively, the animals were euthanized by intravenous overdose injection of thiopental sodium. The teeth and surrounding bone were removed as a block with a water-cooled diamond disc. Untreated teeth from the left quadrants were randomly harvested as controls.

\section{Canal preparation}

After anesthetizing the animals and confirming the presence of open apices in the mandibular and maxillary premolars via pre-operative radiographs, endodontic access was performed, and pulp tissue was completely removed. Teeth were left without coronal restoration for 14 days to allow contamination. After 14 days, animals were anesthetized and canals were cleaned under aseptic conditions to the apices. After drying the canals with sterile paper points, a cotton pellet was placed in the pulp chamber then sealed with a temporary filling for 7 days (Orafil G, Colostol, Fermin, India). On the eighth day, the temporary filling was removed; 120 root canals from 12 dogs were filled with recombinant amelogenin protein RAP (180 amino acid mouse amelogenin) and the other 120 canals were filled with calcium hydroxide.

An intermediate restorative material (IRM) was then carefully placed over the root canal dressing, and the access cavity was restored with amalgam. After 1, 3, or 6 months postoperatively ( 8 dogs per time period), the animals were euthanized, then samples were evaluated.

\section{Histological procedures and immunohistochemistry protocol}

Prepared specimens were stained using hematoxylin and eosin (H\&E) and different immunohistochemical stains. Antibodies for Peripherin, CGRP and SOX2 were obtained from Abcam (Cambridge, UK, ab39374, ab139264 and ab92494 respectively), whereas antibody for GFAP was obtained from Spring Bioscience (CA, USA, M3781). All steps were performed following the manufacturers' instructions. Conjugated secondary antibodies were obtained from Thermo Fisher Scientific (Fremont, CA USA). Sections were imaged using a Nikon Eclipse 80i microscope (Tokyo, Japan).

\section{Data analysis}

Cell counting for stem cells apical papilla SCAP and pulp stem cells PSC: Targeted cells were identified as cells showing positive brown nuclear reaction (DAB chromogen) specific for targeted antigen (Sox2) (SCAP/ pulp stem cells). The microscopic magnification was $\times 400$. Image Pixel scale was standardized for 1000 pixels Microscope used was Light Microscope Olympus CX41RF.

Image analysis for immune-reactivity intensity threshold: The images for immunohistochemistry for Peripherin and GFAP antibodies have been subject to quantitative image analysis for immunoreactivity intensity threshold using the software Image J/FIJI J 1.46/2012. The application provides a comparative quantitation for the reaction intensity of $\mathrm{DAB}$ chromogen illustrating the tissue areas with positive $\mathrm{Ag} / \mathrm{Ab}$ reaction (brown stain) as compared to the areas with negative reaction (grey scale). The measurement scale is expressed as pixels/plot area taking in consideration the inversely proportionate relation between pixel number and stain intensity threshold i.e. the lower the pixel number; the stronger is the stain intensity.

\section{Results}

\section{Amelogenin-treated canal cohort}

At 1 month after treatment, $82.5 \%$ (Table 1) of the canals treated with recombinant amelogenin showed pulp regeneration inside the previously empty root canal, in the form of cellular condensations immune-reactive to Sox2 antibody. The regenerated apical papilla showed intense immunoreactivity to Sox2 antibody (Fig. 1A). Higher magnification of the regenerated pulp and apical papilla showed stem cells (SC) of the regenerated pulp and stem cells of the apical papilla (SCAP), both of which are immune-reactive to Sox2 (Fig. 1B and 1C). The regenerated pulp tissue showed moderate to intense immune-reactive staining for Peripherin (Fig. 1D) in the form of conical arrays at the odontoblast layer and moderate to intense 
Table 1. Summative results

\begin{tabular}{|c|c|c|c|c|}
\hline & $\begin{array}{l}1 \text { month } \\
\%(\#)\end{array}$ & $\begin{array}{l}3 \text { months } \\
\%(\#)\end{array}$ & $\begin{array}{l}6 \text { months } \\
\%(\#)\end{array}$ & $\begin{array}{l}\text { Total } \\
\%(\#)\end{array}$ \\
\hline \multicolumn{5}{|l|}{$\begin{array}{l}\text { Pulp regeneration } \\
\text { observed }\end{array}$} \\
\hline Amelogenin (\#40) & 82.5 & 85 (34) & 87.5 (35) & $85(102)$ \\
\hline $\begin{array}{l}\text { Calcium } \\
\text { hydroxide (\#40) }\end{array}$ & $0.0(0.0)$ & $0.0(0.0)$ & $0.0(0.0)$ & $0.0(0.0)$ \\
\hline \multicolumn{5}{|l|}{$\begin{array}{l}\text { Apical papilla } \\
\text { present }\end{array}$} \\
\hline Amelogenin (\#40) & $100(40)$ & $57.5(23)$ & $0.0(0.0)$ & $52.5(63)$ \\
\hline $\begin{array}{l}\text { Calcium } \\
\text { hydroxide (\#40) }\end{array}$ & $0.0(0.0)$ & $0.0(0.0)$ & $0.0(0.0)$ & $0.0(0.0)$ \\
\hline
\end{tabular}

immunoreactivity in the central area of the root canal space and pulp chamber (Fig. 2A). Apical papillae (AP) surrounding the regenerating root apices were recognized in $100 \%$ of treated premolars (Table 1). AP showed moderate to intense immunoreactivity to peripherin. The presence of CGRP antigen was recognized immunologically in the soft connective tissue within the AP at the root apex and apical and mid-root canal areas. The CGRP-reactive fibers showed moderate to intense immunereactivity running axially in the central area of the root canal in the central pulp region (Fig. 1E). Moderate to intense GFAP reactivity in the odontoblastic and subodontoblastic regions and mild to moderate reactivity throughout the regenerated pulp was observed (Fig. 1F). Intense immunoreactivity to GFAP was seen within the odontoblast cell layer, and as smaller rounded cells throughout the pulp tissue. Mild to moderate immunereactivity to GFAP was recognized in the $\mathrm{AP}$ (Fig. $1 \mathrm{~F}$ and $2 \mathrm{~B}$ ).

At 3 months after treatment, $85 \%$ (Table 1) of the canals treated with recombinant amelogenin showed delicate regenerated pulp tissue that revealed intense immunoreactivity to Peripherin peripherally near the odontoblast areas (Fig. 1G). Moderate immunoreactivity to CGRP antibody was seen at the root canal apices and directed axially towards the central pulp region (Fig. $1 \mathrm{H}$ ). Intense immunoreactivity to GFAP antibody was recognized in the odontoblastic and subodontoblastic regions, while the rest of the pulp revealed mild to moderate immunoreactivity (Fig. 1I). Apical papillae persisted in $57.5 \%$ of cases (Table 1) and showed immunoreactivity to CGRP (Fig. 1H).

At 6 months after treatment, $87.5 \%$ (Table 1) of the canals treated with recombinant amelogenin showed regenerated pulp tissue that revealed intense immunoreactivity to Peripherin in the periphery near the odontoblast region (Fig. 1J). Intensely stained CGRP-reactive fibers were seen entering the central area of the root canal through the apical foramen, and running in an axial direction towards the root canal and mid-root (Fig. 1K). Mild to moderate immunoreactivity to GFAP was seen in the odontoblast and cell rich zone regions (Fig. 1L). No apical papillae were seen (Table 1).

\section{Calcium hydroxide-treated canal cohort}

At 1 month after treatment, $100.0 \%$ of the canals treated with calcium hydroxide showed no immunereactivity to Sox2 in the empty root canals (Fig. 1M).

At 3 months after treatment, $100.0 \%$ of canals showed no soft tissue inside the root canals. No immunoreactivity to Peripherin in root canals is seen. Moderate immune reactivity to peripherin is seen in odontoblast layer (Fig. $1 \mathrm{~N})$.

At 6 months after treatment, $100.0 \%$ of the canals treated with Calcium hydroxide showed no regenerated soft tissue inside root canals. No immunoreactivity to CGRP is recognized. No immunoreactivity to CGRP is recognized in the granulation tissue (Fig. 1O).

\section{Statistical evaluation}

This study was based on an initial sample size of 240 canals harvested and observed over time intervals of 1,3 and 6 months. The recombinant amelogenin cohort in the 1-month time period showed $82.5 \%$ pulp regeneration, and $100 \%$ presence of apical papillae. The 3-month time period showed $85 \%$ pulp regeneration, and $57.5 \%$ presence of apical papillae, whereas the 6-month time period showed $87.5 \%$ pulp regeneration, and $0.0 \%$ presence of apical papillae.

The calcium hydroxide cohort in the three time periods showed $0.0 \%$ pulp regeneration, and $0.0 \%$ presence of apical papillae.

The calcium hydroxide cohort in the 1-month time period showed $0.0 \%$ pulp regeneration and $0.0 \%$ presence of apical papilla. The 3-month time period showed $0.0 \%$ pulp regeneration, and $0.0 \%$ presence of apical papillae, whereas the 6-month time period also showed $0.0 \%$ pulp regeneration and $0.0 \%$ presence of apical papillae.

\section{Data analysis}

Cell counting for stem cells apical papilla and pulp stem cells: Cells were counted in 3 fields for each image. The mean cell count was calculated for each of the SCAP/Pulp SCs.

Images subjected for quantitative analysis for cell counting for Apical Papilla Stem cells SCAP were 1115-11191150-1151. 
Images subjected for quantitative analysis for cell counting of Pulp Stem cells were 1117-1811-1812.

The results of mean cell count for each of the stem cells apical papilla/pulp stem cells have been transported to excel sheets to be presented as bar chart graphs. The mean of total count has been compared for each of the apical
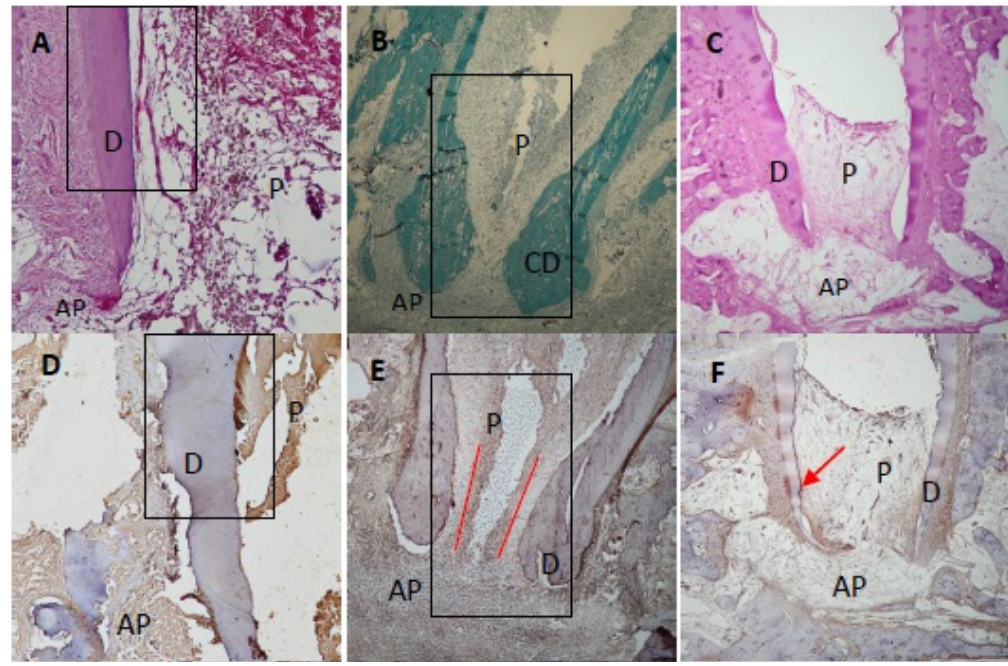

Fig. 1. Premolar teeth at selected time intervals following treatment with recombinant amelogenin and calcium hydroxide. (A) Apical and mid root area of a premolar tooth 1-month post treatment with $\mathrm{r}$-amelogenin showing regenerated cellular tissue inside canal consistent with pulp tissue (P), and apical papilla (AP) and dentin (D). H\&E stain. Original magnification, $\times 100$. (B) Apical and mid root area of a premolar tooth 1-month post treatment with $r$-amelogenin showing cells in the regenerated pulp tissue $(\mathrm{P})$, apical papilla (AP) and cellular dentin (CD) Trichrome stain. Original magnification, $\times 100$. (C) Apical area of premolar tooth 1-month post treatment with r-amelogenin showing regenerated regenerated pulp tissue (P) in the root canal, dentin (D) and apical papilla (AP). H\&E stain. Original magnification, $\times 100$. (D) Apical and mid-root area of premolar tooth 1-month post treatment with r-amelogenin showing intense to moderate immunoreactivity to the peripherin (PER) protein. Intense immunoreactivity is observed at the odontoblast layer and odontoblastic zone in the form of parallel conical arrays. Moderate to intense immunoreactivity in the central root canal and pulp camber. Strong immunoreactivity is seen in the apical papilla (AP). Dentin (D). Peripherin antibody. Original magnification, $\times 100$. (E) Apical area of premolar tooth 1-month post treatment with r-amelogenin showing intense to moderate immunoreactivity to the CGRP antigen in the cells of the apical papilla (AP) running axially in the central area of root canal (red lines). Dentin (D). CGRP antibody. Original magnification, $\times 100$. (F) Apical area of premolar tooth 1-month post treatment with r-amelogenin showing intense immunoreactivity to the GFAP antibody in the odontoblastic region (arrow) and mild to moderate immunoreactivity throughout the regenerated pulp tissue. Mild immunoreactivity is seen in the cells of the apical papilla (AP). Dentin (D). GFAP antibody. Original magnification, $\times 40$. (G) Apical area of premolar tooth 3-month post treatment with $r$-amelogenin showing intense immunoreactivity to peripherin antibody in the regenerated pulp tissue $(P)$ that lies at the pulp periphery near the odontoblast area (red lines). Dentin (D), periodontal ligament PDL (black arrow). Peripherin antibody. Original magnification, $\times 40$. $(\mathrm{H})$ Apical area of premolar tooth 3-month post treatment with r-amelogenin showing moderate to intense immunoreactivity to CGRP antibody in the regenerated pulp tissue (P) that lies at root canal apex and in mid root in the central pulp region (red lines). Apical papilla (AP) shows moderate immunoreactivity. Dentin (D). CGRP antibody. Original magnification, $\times 100$. (I) Apical area of premolar tooth 3-month post treatment with r-amelogenin showing moderate to intense immunoreactivity to GFAP antibody in the odontoblastic region (red arrow) and mild to moderate immunoreactivity throughout the regenerated pulp tissue (P). Dentin (D), periodontal ligament PDL (black arrow). GFAP antibody. Original magnification, $\times 100$. (J) Apical area of premolar tooth 6-month post treatment with r-amelogenin showing intense immunoreactivity to peripherin antibody in the regenerated pulp tissue (P) that lies at pulp periphery near the odontoblast area (red lines). Dentin (D), PDL (black arrow). Peripherin antibody. Original magnification, $\times 100$. (K) Apical area of premolar tooth 6-month post treatment with r-amelogenin showing intense immunoreactivity to CGRP antibody in the regenerated pulp tissue (P) that lies at root canal apex and in mid root in the central pulp region (red lines). Dentin (D), PDL (black arrow). CGRP antibody. Original magnification, $\times 100$. (L) Apical and mid area of premolar tooth 6-month post treatment with r-amelogenin showing moderate to intense immunoreactivity to GFAP antibody in the odontoblastic and cell-rich zone regions (red arrows) and mild to moderate immunoreactivity throughout the regenerated pulp tissue (P). Dentin (D), PDL (black arrow). GFAP antibody. Original magnification, $\times 100$. (M) Apical area of premolar tooth 1-month post treatment with calcium hydroxide showing no immunoreactivity to Sox2 antibody in the empty root canals (RC). Dentin (D). Mineralized island can be seen in the empty RC (box). Sox2 antibody. Original magnification, $\times 100$. (N) Apical and mid root area of a premolar tooth 3-month post treatment with calcium hydroxide showing empty root canals (RC). Odontoblast cell shows intense immunereactivity to peripherin antibody. Dentin (D). Granulation tissue (GT) shows mild immune reactivity to peripherin antibody. Peripherin antibody. Original magnification, $\times 100$. (O) Apical area of premolar tooth 6-month post treatment with calcium hydroxide showing no immunoreactivity to CGRP antibody in the empty root canals (RC). Dentin (D). Granulation tissue shows no immunereactivity to CGRP antibody. CGRP antibody. Original magnification, $\times 100$. 
Fig. 1. Continued.

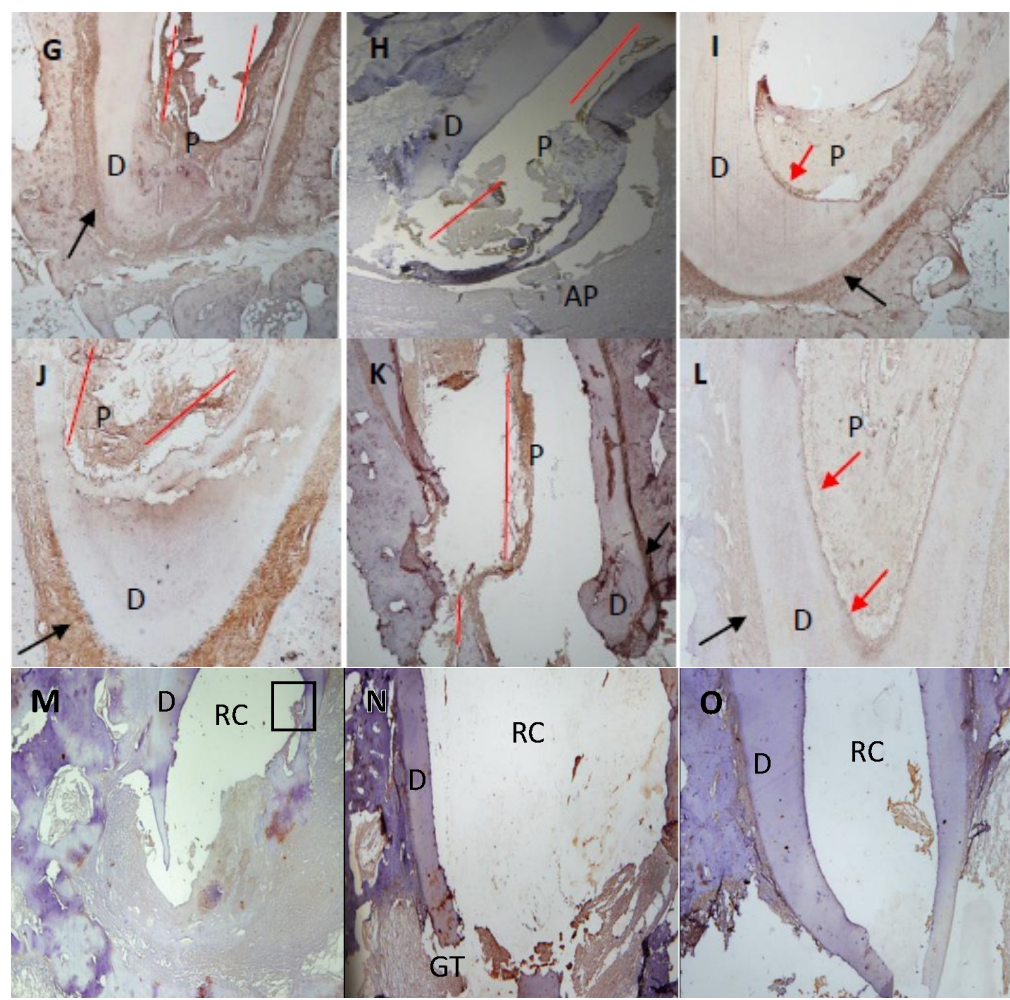

and pulp stem cells, and then merged into a single bar chart graph (Fig. 3).

Image Analysis Software used is Olympus Cell Imaging Solution Software- Life Science Microscopy - 2010.

\section{Image analysis for immunoreactivity intensity threshold}

The positive peripherin $\mathrm{Ag} / \mathrm{Ab}$ immunostaining (brown DAB chromogen) were detected in 9 out of 13 plotted areas. These revealed an average of 161209 pixels for the stain intensity threshold. In contrast, there were 4 out of 13 plotted areas showing negative peripherin $\mathrm{Ab} / \mathrm{Ab}$ reactivity (grey scale) with an average of 537127 pixels/plot area (Fig. 2A- Peripherin. Ab)

The positive GFAP $\mathrm{Ag} / \mathrm{Ab}$ immunostaining (brown DAB chromogen) were detected in 20 out of 22 plotted areas. These revealed an average of 342321 pixels for the stain intensity threshold. In contrast, there were 2 out of 22 plotted areas showing negative GFAP $\mathrm{Ab} / \mathrm{Ab}$ reactivity (grey scale) with an average of 817050 pixels/plot area (Fig. 2B- GFAP).

\section{Discussion}

A biological approach to restoring tooth structure through the application of regenerative endodontics aims to replace inflamed/necrotic pulp tissue with regenerated pulp-like tissue to revitalize teeth and improve quality of life $(3,18)$.

There is very limited histologic information regarding characteristics of tissues formed in the root canal space of human teeth after regenerative endodontics. Wang et al. (19) reported on the growth of new vital tissue into the pulp space. Previous studies collectively showed that when disinfected canals of teeth with open apices are treated with regenerative endodontics, tissues of the periodontium (consisting of fibrotic periodontal ligament, collagen fibers, blood vessels, and cementum- and bone-like tissues) can grow into the root canals of these teeth $(4,20-22)$.

Current treatment approaches tend to stimulate more reparative than regenerative responses, such that the newly formed tissue does not closely resemble the physiological structure of dental pulp (23). Although vascularized pulp-like tissues have been reported in some experimental studies, little is known about the constituents of the regenerated tissue. Pulp regeneration is a crucial measure of the success of endodontic therapy. Angiogenesis, vasculogenesis and neurogenesis are essential for true pulp regeneration (24-26).

In a previous study, the effect of recombinant amelogenin was examined using a similar protocol on 24 dogs. 

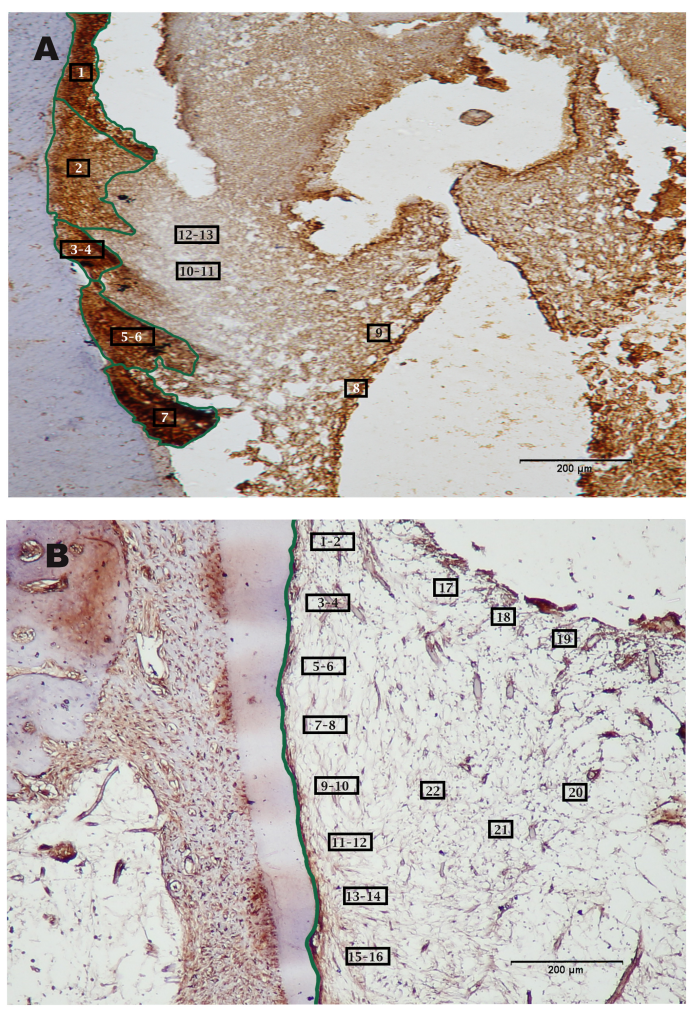

Fig. 2. Premolar teeth at 1-month time interval following treatment with recombinant amelogenin. (A) Higher magnification of box in Fig. 1D showing positive peripherin $\mathrm{Ag} / \mathrm{Ab}$ immunostaining (brown DAB chromogen) in 1 $\sim 9$ of 13 of the plotted areas, while 10 13 of the plotted areas show negative peripherin $A b / A b$ reactivity (grey scale). Image analysis. Peripherin antibody. Original magnification, $\times 400$. (B) Higher magnification of Fig. $1 F$ showing positive GFAP $\mathrm{Ag} / \mathrm{Ab}$ immunostaining (brown DAB chromogen) were detected in $1 \sim 20$ out of 22 plotted areas. In contrast, $21 \sim 22$ of the plotted areas showed negative GFAP Ab/Ab reactivity (grey scale). Image analysis. GFAP antibody. Original magnification, $\times 400$.

Half of the root canals in this study were filled with RAP and the other half with calcium hydroxide. Only the amelogenin group showed pulp regeneration. After removal of the entirety of the pulp from infected, non-vital, openapex permanent teeth, nearly $85 \%$ of the 120 canals treated with RAP showed regeneration of tissue similar to the authentic pulp, while the 120 canals treated with calcium hydroxide were empty (17).

Stem cells present in the wound area after endodontic treatment of a tooth with periapical periodontitis were mainly mesenchymal stem cells (MSCs), stem cells of the apical papilla (SCAP) and to a lesser extent bone marrow stem cells and periodontal ligament stem cells (25). The signalling molecules chosen to induce pulp regeneration should facilitate the recruitment of stem cells with vasculogenic and neurogenic differentiation potential. RAP is

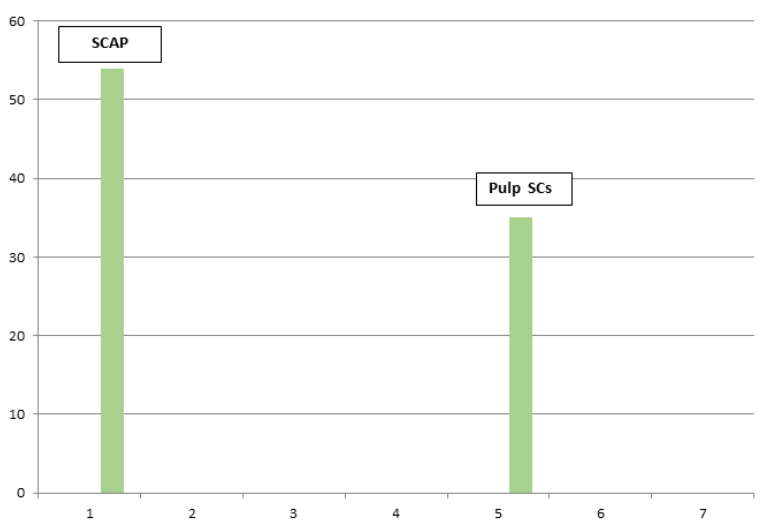

Fig. 3. Mean count for stem cells apical papilla SCAP + pulp stem cells. Quantitative image analysis immunohistochemical sections comparing between mean counts for SCAP+pulp stem cells (1000 pixel image scale/Mic. Mag. $\times 400$ ).

known for its ability to up-regulate angiogenic and neurogenic differentiation $(27,28)$. It seems that recombinant amelogenin signals for the recruitment of stem cells. For this reason, we used recombinant amelogenin protein (RAP) to induce pulp regeneration in the present study.

In the present work, the regenerated tissues surrounding the root apices showed immune reactivity to Sox2, peripherin, CGRP and GFAP. Apical papillae persisted until the third post-operative month in $57.5 \%$ of cases. The periodontal ligament also showed immunoreactivity to neural antibodies.

Of particular interest is the fact that the regenerated pulp in the present study showed intense immunoreactivity to Sox 2 antibody. Sox 2 is one of the three core intrinsic factors for regulating pluripotency (13). In addition, Sox 2 has been identified as a lineage specified for stem cell differentiation (29). Thus, Sox2 is one of the critical factors that controls somatic cell programming and neural differentiation in addition to maintaining the self-renewal of neural progenitor stem cells $(14,15)$. The presence of immunoreactivity to Sox 2 in the early stages of dental pulp regeneration indicates neural initiation and differentiation. It is highly expressed in proliferating neural progenitor cells in apical papilla and to a lesser degree in pulp stem cells and is also expressed in post-mitotic neuronal and glial cells (30). This transcription factor may be partly responsible for regulating the pluripotency and self-renewal of SCAP surrounding the regenerated root apices, and their adoption of a neural fate, in addition to inducing stem cells in the regenerated pulp. The use of recombinant amelogenin in regenerative endodontics induces the expression of Sox 2 by pluripotent SCAP surrounding the growing roots and by regenerated stem cells 
inside the root canals. Sox2 directs tissue-resident adult stem/progenitor cells to take advantage of the latent endogenous regenerative potential of the body and local tissue responses to regenerate delicate pulp tissue. This tissue regeneration method relies on endogenous stem/progenitor cell homing and presents an alternative to stem cell transplantation $(12,31)$.

The regenerated pulp in the present study also showed immunohistological evidence of the regeneration of peripherin neuronal intermediate filaments (A-fibers) in the pulp periphery in close proximity to the odontoblast cell layer (11), and CGRP-reactive central nerves (C-fibers) in the pulp core (13).

The newly formed pulp tissue with regenerated sensory nerves filled the previously empty pulp space. The regenerated pulp showed a similar distribution pattern of peripherin neurofilaments and axons expressing CGRP to that of the authentic pulp innervation.

GFAP immunoreactivity is recognized documenting astrocytic differentiation outside the CNS. Cell populations in regenerated dental pulp showed GFAP immunoreactivity, which was identified in peripheral human dental pulp in the odontoblast area and at the periphery of the regenerated pulp demonstrating a sophisticated neuronal structure (14). Glial cells have multiple functions during the repair process of the (PNS), axonal signals are critical for Schwann cell migration, survival and proliferation (11).

There was no pulp tissue regenerated in the calcium hydroxide group in all the three time periods. The granulation tissue was always at a distance from the root apices and showed no immunoreactivity to either Sox 2 antibody or CGRP antibody. Iimmunereactivity to peripherin was seen in the odontoblastic cell region only.

Further experimental support is needed to improve biological outcomes and develop treatment therapies that will eliminate the use of any artificial material, thereby enabling replacement of lost tissues with natural bodily resources and contributing to improvements in clinical treatment protocols.

\section{Acknowledgments}

The authors acknowledges Misr El Kheir Foundation, Egypt, for the grant that they have given to this project. Moreover, the authors acknowledges Professor Malcolm L Snead, Centre for Craniofacial Molecular Biology, Herman Ostrow School of Dentistry of USC, the University of Southern California, for providing the recombinant protein and for his support and guidance and also Dr. Bridget Samuel for reviewing the manuscript.

This work was supported by Misr El Kheir Foundation,
Egypt with Grant Number: 3993, however, the foundation has no involvement of whatsoever nature in the preparation of the article, study design, collection, analysis and interpretation of data including the submission of this article for publication.

\section{Potential Conflict of Interest}

The authors have no conflicting financial interest.

\section{References}

1. Chai Y, Jiang X, Ito Y, Bringas P Jr, Han J, Rowitch DH, Soriano P, McMahon AP, Sucov HM. Fate of the mammalian cranial neural crest during tooth and mandibular morphogenesis. Development 2000;127:1671-1679

2. Fried K, Gibbs JL. Dental pulp innervation 6. In: Goldberg $M$, editor. The Dental Pulp: Biology, Pathology, and Regenerative Therapies. Berlin Heidelberg: Springer; 2014. 75-95

3. Chandki R, Kala M, Banthia P, Banthia R. From stem to roots: Tissue engineering in endodontics. J Clin Exp Dent 2012;4:e66-e71

4. Yamauchi N, Nagaoka H, Yamauchi S, Teixeira FB, Miguez P, Yamauchi M. Immunohistological characterization of newly formed tissues after regenerative procedure in immature dog teeth. J Endod 2011;37:1636-1641

5. Lin LM, Di Fiore PM, Lin J, Rosenberg PA. Histological study of periradicular tissue responses to uninfected and infected devitalized pulps in dogs. J Endod 2006;32:34-38

6. Sharma S, Sikri V, Sharma NK, Sharma VM. Regenration of tooth pulp and dentin: trends and advances. Ann Neurosci 2010;17:31-43

7. Kim TH, Bae YC, Yang ES. Distribution of peripherin immunoreactive axons in rat molar pulp. Korean J Phys Anthropol 2013;26:33-40

8. Magloire H, Maurin JC, Couble ML, Shibukawa Y, Tsumura M, Thivichon-Prince B, Bleicher F. Topical review. Dental pain and odontoblasts: facts and hypotheses. J Orofac Pain 2010;24:335-349

9. Uddman R, Grunditz T, Sundler F. Calcitonin gene related peptide: a sensory transmitter in dental pulps? Scand J Dent Res 1986;94:219-224

10. Veerayutthwilai O, Luis NA, Crumpton RM, MacDonald GH, Byers MR. Peripherin- and CGRP-immunoreactive nerve fibers in rat molars have different locations and developmental timing. Arch Oral Biol 2006;51:748-760

11. Kökten T, Lesot H, Kuchler-Bopp S. Experimental design for the innervation of tooth forming from implanted cell re-associations. In: Eberli D, editor. Cells and Biomaterials in Regenerative Medicine. Rijeka: IntechOpen; 2014. 345-373

12. Chen FM, Wu LA, Zhang M, Zhang R, Sun HH. Homing of endogenous stem/progenitor cells for in situ tissue regeneration: promises, strategies, and translational perspectives. Biomaterials 2011;32:3189-3209 
13. Yeo JC, $\mathrm{Ng} \mathrm{HH}$. The transcriptional regulation of pluripotency. Cell Res 2013;23:20-32

14. Zhang L, Yuan G, Liu H, Lin H, Wan C, Chen Z. Expression pattern of Sox 2 during mouse tooth development. Gene Expr Patterns 2012;12:273-281

15. Zhang S, Cui W. Sox2, a key factor in the regulation of pluripotency and neural differentiation. World J Stem Cells 2014;6:305-311

16. Farahani RM, Simonian M, Hunter N. Blueprint of an ancestral neurosensory organ revealed in glial networks in human dental pulp. J Comp Neurol 2011;519:3306-3326

17. Mounir MM, Matar MA, Lei Y, Snead ML. Recombinant amelogenin protein induces apical closure and pulp regeneration in open-apex, nonvital permanent canine teeth. J Endod 2016;42:402-412

18. Hargreaves KM, Diogenes A, Teixeira FB. Treatment options: biological basis of regenerative endodontic procedures. J Endod 2013;39(3 Suppl):S30-S43

19. Wang X, Thibodeau B, Trope M, Lin LM, Huang GT. Histologic characterization of regenerated tissues in canal space after the revitalization/revascularization procedure of immature dog teeth with apical periodontitis. J Endod 2010;36:56-63

20. Nakashima M, Akamine A. The application of tissue engineering to regeneration of pulp and dentin in endodontics. J Endod 2005;31:711-718

21. Nör JE. Tooth regeneration in operative dentistry. Oper Dent 2006;31:633-642

22. Smith AJ, Lumley PJ, Tomson PL, Cooper PR. Dental re- generation and materials: a partnership. Clin Oral Investig 2008;12:103-108

23. Simon S, Smith AJ. Regenerative endodontics. Br Dent J 2014;216:E13

24. Janjić K, Cvikl B, Moritz A, Agis H. Dental pulp regeneration: in vitro and in vivo approaches. Int J Stomatol Occlusion Med 2016;8:1-9

25. Nakashima $M$, Iohara $K$. Regeneration of dental pulp by stem cells. Adv Dent Res 2011;23:313-319

26. Yang J, Yuan G, Chen Z. Pulp regeneration: current approaches and future challenges. Front Physiol 2016;7:58

27. Amin HD, Olsen I, Knowles J, Dard M, Donos N. A tyrosine-rich amelogenin peptide promotes neovasculogenesis in vitro and ex vivo. Acta Biomater 2014;10:1930-1939

28. Jonke E, Gemperli AC, Zhang T, Özdemir B, Dard M, Rausch-Fan X, Andrukhov O. Effect of tyrosine-rich amelogenin peptide on behavior and differentiation of endothelial cells. Clin Oral Investig 2016;20:2275-2284

29. Wang Z, Oron E, Nelson B, Razis S, Ivanova N. Distinct lineage specification roles for NANOG, OCT4, and SOX2 in human embryonic stem cells. Cell Stem Cell 2012;10: $440-454$

30. Graham V, Khudyakov J, Ellis P, Pevny L. SOX2 functions to maintain neural progenitor identity. Neuron 2003;39: 749-765

31. Mimeault M, Batra SK. Great promise of tissue-resident adult stem/progenitor cells in transplantation and cancer therapies. Adv Exp Med Biol 2012;741:171-186 